\title{
UPAYA PENYELESAIAN SENGKETA WILAYAH PERBATASAN DARAT \\ INDONESIA - TIMOR LESTE
}

\author{
Imelda Masni Juniaty Sianipar \\ imelda.sianipar@uki.ac.id
}

Universitas Kristen Indonesia

\begin{abstract}
On the Annual Press Statement of the Indonesian Minister for Foreign Affairs 2017, Minister for Foreign Affairs, Retno LP Marsudi stated that Indonesia will accelerate the settlement of negotiations on the border issues of Indonesia with several neighboring countries including Timor Leste. Foreign Minister Retno also stressed that the settlement of Indonesia's border with Timor-Leste will be peaceful, without threat of violence, and with full respect for international law. This article seeks to understand the border dispute of the border areas of Indonesia-Timor Leste in international relations perspective. There are three strategies that Indonesia can implement to resolve this dispute. They are military confrontation, the use of formal institutions such as international organizations and the use of informal institutions such as norms, beliefs, ideas and values. The article argues that it is not enough to rely solely on international agreements to resolve the dispute between Noel Besi / Citrana and Bijael Sunan / Oben, Indonesia needs to emphasize the importance of understanding the norms, beliefs, ideas and values of indigenous peoples living in disputed territories. It is expected that the use of formal and informal institutions can accelerate the settlement of dispute Noel Besi / Citrana and Bijael Sunan / Oben.
\end{abstract}

Keywords: land border dispute, Indonesia, Timor Leste

\section{Abstrak}

Pada Pernyataan Pers Tahunan Menteri Luar Negeri Tahun 2017, Menteri Luar Negeri (Menlu) Retno LP Marsudi menyatakan bahwa Indonesia akan mempercepat penyelesaian perundingan masalah perbatasan wilayah Indonesia dengan beberapa negara tetangga, salah satunya adalah Timor Leste. Menlu Retno juga menekankan bahwa penyelesaian perbatasan Indonesia dengan Timor Leste akan dilakukan secara damai, tanpa ancaman kekerasan, dan dengan penghormatan sepenuhnya pada hukum internasional. Artikel ini berupaya memahami sengketa perbatasan wilayah perbatasan Indonesia-Timor Leste dalam perspektif hubungan internasional. Ada tiga strategi yang dapat ditempuh oleh Indonesia dalam rangka menyelesaikan sengketa ini yaitu konfrontasi militer, penggunaan institusi formal seperti organisasi internasional serta penggunaan institusi informal yaitu norma, kepercayaan, ide dan nilai. Artikel ini berargumen bahwa untuk menyelesaikan sengketa Noel Besi/Citrana dan Bijael Sunan/Oben tidak cukup menggandalkan traktat / perjanjian internasional saja, Indonesia perlu lebih menekankan pada pentingnya pemahaman akan norma, kepercayaan, ide dan nilai dari masyarakat adat yang tinggal di wilayah sengketa tersebut. Niscaya penggabungan strategi pemanfaatan institusi formal dan informal tersebut dapat mempercepat penyelesaian sengketa Noel Besi/Citrana dan Bijael Sunan/Oben.

Kata kunci: sengketa wilayah perbatasan darat, Indonesia, Timor Leste

\section{Pendahulan}

Perbatasan merupakan wilayah yang memiliki posisi penting dalam tatanan kehidupan bernegara (Wuryandari, 2017, h. 63). Wilayah NKRI (Negara Kesatuan Republik Indonesia ) berbatasan dengan banyak negara. Di darat, wilayah NKRI berbatasan dengan wilayah 3 (tiga) negara lain yaitu Malaysia, Papua Nugini, dan Timor Leste. Sedangkan di wilayah laut,
Wilayah NKRI berbatasan dengan 10 negara yaitu Malaysia, Papua Nugini, Singapura, Republik Demokratik Timor Leste, India, Thailand, Vietnam, Filipina, Republik Palau dan Australia. Pengelolaan batas-batas Wilayah Negara diperlukan dan sangat penting untuk memberikan kepastian hukum mengenai ruang lingkup wilayah negara, kewenangan pengelolaan Wilayah Negara, 
dan hak-hak berdaulat (Badan Nasional Pengelola Perbatasan, 2010).

Sampai tahun 2017, Indonesia masih memiliki beberapa sengketa perbatasan darat dan laut dengan beberapa negara tetangga antara lain batas darat dengan Timor Leste, batas wilayah laut dan darat dengan Malaysia, serta batas landas kontinen dengan Filipina. Dalam Pernyataan Pers Tahunan Menteri Luar Negeri Tahun 2017, Menteri Luar Negeri (Menlu) Retno Marsudi menyatakan bahwa Indonesia akan mempercepat penyelesaian perundingan masalah perbatasan wilayah Indonesia dengan negara-negara tetangga termasuk diantaranya adalah Timor Leste (Marsudi, 2017).

Perbatasan darat antara Indonesia Timor Leste memiliki panjang $268.8 \mathrm{~km}$, melintasi 3 kabupaten di Provinsi Nusa Tenggara Timur, yaitu Kabupaten Belu, Timor Tengah Utara dan Kupang. Perbatasan darat RI dengan Timor Leste terbagi atas dua sektor, yaitu: (1) Sektor Timur (Sektor utama/main sector) di Kabupaten Belu yang berbatasan langsung dengan Distrik Covalima dan Distrik Bobonaro di Timor Leste sepanjang 149.1 kilometer; dan (2) Sektor Barat (Kabupaten Kupang dan Kabupaten Timor Tengah Utara) yang berbatasan langsung dengan Distrik Oecussi merupakan wilayah enclave Timor Leste sepanjang $119.7 \mathrm{~km}$. Hampir sebagian besar (99\%) batas darat kedua negara berupa batas alam berupa watershed dan thalweg (bagian terdalam sungai). Delimitasi batas RI dengan Timor-Leste di Pulau Timor mengacu kepada perjanjian antara Pemerintah Hindia Belanda dan Portugis pada tahun 1904 dan Permanent Court Award (PCA) 1914, serta Perjanjian Sementara antara Indonesia dan Timor Leste pada tanggal 8 April 2005. Perundingan perbatasan antara RI dengan Timor Leste mulai dilaksanakan sejak tahun 2001 dengan diadakannya pertemuan pertama Technical SubCommitee on Border Demarcation and Regulation (TSCBDR) RI-UNTAET (United Nations Transitional Administration for East Timor). Batas negara antara RI dan Timor Leste sebanyak 907 titik-titik koordinat telah ditetapkan dalam persetujuan tentang Perbatasan Darat (Provisional Agreement) yang ditandatangani oleh Menlu RI dan Menlu Timor Leste pada tanggal 8 Juni 2005 di Dili namun masih ada segmen yang belum terselesaikan dan yang belum disurvey/diukur oleh Tim Survey kedua negara (Badan Nasional Pengelola Perbatasan, 2010). Hingga tahun 2013, terdapat tiga segmen yang belum disepakati yaitu segmen Noel Besi/Citrana, Manusasi/Oben dan segmen Dilumil/Memo. Namun pada tahun 2013, segmen Dilumil/Memo diselesaikan melalui Addendum PA 2005. Karenanya hingga tahun 2017 ini, masih tersisa dua segmen yang belum selesai yaitu segmen Noel Besi/Citrana dan Manusasi/Oben (Lailissaum, Pemotretan Udara Wilayah Unresolved Segment Perbatasan RIRDTL dalam Rangka Penyelesaian Sengketa Batas Negara, 2015).

Wilayah perbatasan Noel Besi/Citrana terletak di antara wilayah Kabupaten Kupang, Nusa Tenggara Timur (Indonesia) dan Kabupaten Ambeno yang merupakan bagian dari Wilayah Timor Leste. Daerah ini dialiri Sungai Noel Besi yang bermuara di selat Ombai dimana sejak jaman Portugis aliran sungai mengalir di sebelah kiri daerah sengketa. Dengan adanya perubahan iklim sepanjang tahun dan perubahan alam, menyebabkan aliran sungai bergeser ke arah kanan daerah sengketa yang merupakan lahan pertanian subur. Lahan tersebut merupakan warisan turun temurun dengan batas sungai Noel Besi yang sekarang ada. Sementara wilayah 
Bijael Sunan-Oben merupakan perbatasan antara Kabupaten Timor Tengah Utara yang menjadi bagian dari Indonesia dan distrik Oecusse yang merupakan bagian Timor Leste. Luasnya sekitar 142,7 hektar dan tidak ada penduduk yang tinggal di daerah ini (nasional.kompas.com, 2017).

Sengketa wilayah perbatasan darat Indonesia - Timor Leste merupakan suatu hal yang menarik untuk dikaji pasalnya Timor Leste pada awalnya adalah bagian dari NKRI. Namun sejak tahun 1999, Timor Leste atau yang sebelumnya dikenal dengan Timor Timur melepaskan diri dari NKRI dan menjadi negara merdeka pada tahun 2000. Dengan demikian dapat dikatakan bahwa Indonesia-Timor Leste pada awalnya adalah "bersaudara". Masyarakat yang tinggal di daerah perbatasan IndonesiaTimor Leste pun banyak yang memiliki hubungan kekerabatan. Setelah Timor Leste merdeka, masyarakat di daerah perbatasan tersebut tiba-tiba harus berpisah. Aktivitas masyarakat pun harus disesuaikan dengan situasi dimana mereka berdiam. Melihat kompleksitas kasus ini maka artikel ini berupaya memahami sengketa perbatasan darat IndonesiaTimor Leste dan mencoba menemukan solusi bagi sengketa tersebut dilihat dari perspektif hubungan internasional.

Gambar 1. Peta Perbatasan Indonesia Timor Leste

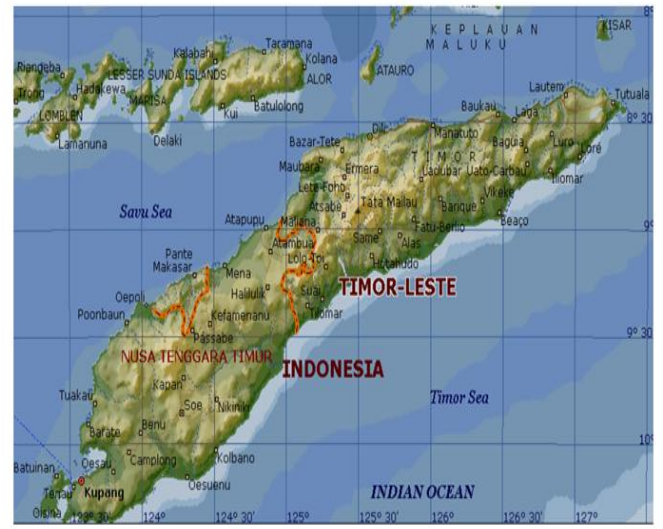

Sumber : Sutisna, Sobar; Handoyo, Sri, 2006

\section{Definisi Perbatasan dan Upaya Penyelesaian Sengketa Perbatasan}

Istilah perbatasan didefinisikan secara beragam. Menurut Encyclopedia of Global Studies, perbatasan merupakan tanda-tanda yang membatasi wilayah negara-bangsa dan yurisdiksi legal, membedakan satu negara dari negara lain, dan membatasi domestik dari dunia internasional. Lucius Caflisch secara umum mendefinisikan perbatasan sebagai cara untuk mengidentifikasi wilayah dimana kedaulatan negara berada (Baker, 2015). Menurut Pusat Penelitian PolitikLIPI, perbatasan (border) mengacu pada garis imajiner yang menandai sebuah batas wilayah yang diambil berdasarkan sebuah keputusan politik, melibatkan dua negara (atau lebih), tertuang dalam sebuah kesepakatan tertulis legal yang diakui oleh pihak - pihak yang bersepakat di dalamnya (Noveria, Mita; Noor, Firman, 2017, h. 11).

Dalam perspektif hubungan internasional $(\mathrm{HI})$, penyelesaian sengketa perbatasan paling tidak dapat ditempuh melalui tiga cara yaitu penggunaan kekuatan militer, penggunaan institusi formal dan penggunaan institusi informal. Penyelesaian sengketa perbatasan melalui penggunaan kekuatan militer atau konfrontasi militer merupakan solusi yang ditawarkan oleh kelompok realisme. Menurut kaum realisme, hubungan internasional pada dasarnya adalah konfliktual dan bahwa konflik internasional pada akhirnya diselesaikan melalui perang. Kelompok realisme menjunjung tinggi nilai-nilai keamanan nasional dan kelangsungan hidup negara (Jackson, Robert; Sorensen, Georg , 2005, h. 88). Kelompok realisme meyakini bahwa integritas wilayah merupakan hal penting untuk mendefinisikan sebuah negara. Untuk itu, negara tidak akan bersedia memberikan wewenang kepada pihak ketiga untuk melakukan intervensi 
jika menyangkut hal-hal yang substantif seperti integritas wilayah (Whitaker, 2013). Kelompok realisme juga meyakini bahwa negara dan pemerintahan lainnya tidak akan pernah dapat diharapkan sepenuhnya karena pada hakekatnya masing-masing negara dan pemerintahan akan berusaha untuk mengejar kepentingan nasional mereka. Kelompok realisme memandang bahwa perjanjianperjanjian, persetujuan, konvensi, kebiasaan, aturan, hukum dan lainnya hanyalah berupa pengaturan bijaksana yang dapat dan akan dikesampingkan jika semua itu berseberangan dengan kepentingan vital negara termasuk didalamnya adalah integritas wilayah (Jackson, Robert; Sorensen, Georg , 2005, h. 89-90).

Kelompok liberalisme menawarkan sebuah solusi yang berbeda dari kelompok realisme dalam rangka menyikapi dinamika politik internasional. Menurut Burchill (2009), kelompok liberalisme mendorong negara untuk mengejar kekuatan ekonomi dan kebutuhan akan kerjasama. Namun karena politik internasional dipandang anarki maka ada kekhawatiran yang dirasakan terkait dengan kerjasama. Untuk menghilangkan kekhawatiran tersebut maka perlu dibangun sebuah institusi baik formal maupun informal. Menurut Keohane (1988), keberadaan institusi penting untuk mendorong kerjasama dan menjaga keberlangsungan kerjasama. Kelompok liberalisme meyakini bahwa institusiinstitusi mampu membatasi resiko dan meyakinkan para pihak bahwa kerjasama lebih membawa keuntungan daripada kerugian. Karena pengaruh institusi, negara menjadi saling ketergantungan dan karenanya lebih selaras dengan kerjasama dan perdamaian daripada mengejar permusuhan. Karenanya, kelompok liberalisme memandang bahwa konflik muncul sebagai akibat kurangnya integrasi ekonomi dan tidak adanya institusi formal yang dapat mengarahkan perilaku negara secara tepat. Kelompok liberalisme sangat meyakini bahwa tanpa kerjasama dan perjanjian maka konflik akan terus ada (Whitaker, 2013, h. 13).

Solusi selanjutnya yang dapat ditawarkan oleh studi hubungan internasional terkait penyelesaian sengketa wilayah adalah penggunaan institusi informal seperti norma, kepercayaan, ide dan nilai yang dikemukakan oleh kelompok konstruktivisme. Kontruktivisme percaya bahwa norma, kepercayaan, ide dan nilai menentukan bagaimana para aktor berperilaku dalam arena internasional (Whitaker, 2013, h. 13). Kelompok konstruktivisme yakin bahwa dunia sosial bukanlah sesuatu yang given; dunia sosial bukan sesuatu "di luar sana". Dunia sosial merupakan wilayah intersubjektif; dunia sosial sangat "berarti" bagi masyarakat yang membuatnya dan hidup di dalamnya, dan yang memahaminya. Dunia sosial dibuat atau dibentuk oleh masyarakat pada waktu dan tempat tertentu (Jackson, Robert; Sorensen, Georg , 2005, h. 307). Bagi konstruktivisme, konflik, persaingan maupun kerjasama merupakan hasil dari pemahaman, harapan dan pengetahuan bersama para aktor-aktor internasional. Tiga hal tersebut menciptakan aktor-aktor dalam suatu situasi dan sifat hubungan mereka, apakah kooperatif ataupun konfliktual (Wendt, 1992, h. 396). Kelompok konstruktivisme menggunakan norma dan keyakinan untuk menjelaskan peristiwa-peristiwa internasional karenanya kelompok konstruktivisme berjuang untuk mendefinisikan secara tepat bagaimana merubah norma dan kepercayaan. Namun hal ini bukanlah pekerjaan mudah karena ketika budaya telah terinstitusionalisasi maka sulit untuk merubahnya (Flockhart, 2016, h. 83). Hal ini kemudian menjadi salah satu 
kelemahan dari perspektif konstruktivisme karena dibutuhkan waktu lama untuk merubah norma dan kepercayaan. Oleh sebab itu, perspektif konstruktivisme jarang digunakan untuk memprediksi terutama jika berkaitan dengan sengketa dan konflik yang membutuhkan resolusi cepat dari para pembuat keputusan. Namun bukan tidak mungkin, perspektif ini dapat digunakan untuk menjadi alternatif dalam penyelesaian sengketa atau konflik (Whitaker, 2013, h. 13).

\section{Sejarah dan Latar Belakang Sengketa Perbatasan Darat Indonesia - Timor Leste}

Keluarnya Timor Timur dari bagian negara Indonesia menjadi negara sendiri yakni Republik Demokratika Timor Leste, dinilai sebagai awal atau cikal bakal munculnya sengketa wilayah perbatasan antara Indonesia- Timor Leste. (www.viva.co.id, 2016). Pada 30 Agustus 1999, Perserikatan Bangsa - bangsa melaksanakan referendum untuk menentukan nasib Timor Timur di masa yang akan datang dan berdasarkan referendum tersebut, sekitar 80 persen rakyat Timor Timur memilih merdeka dan memisahkan diri dari Indonesia (Handoyo, Sri, 2014, h. 178). Selanjutnya pada bulan Oktober 1999, MPR RI mengeluarkan Ketetapan MPR No. V/MPR/1999 tentang pencabutan Ketetapan MPR No. IV/1978 yang berisikan tentang integrasi Timor Timur (Pertahanan, 2007).

Sebagai konsekuensi logis dari pemisahan tersebut adalah Pemerintah Indonesia dan Timor Leste harus segera menentukan garis batas negara untuk dijadikan dasar pengelolaan wilayah masing - masing. Pada tahun 2000, Pemerintah Indonesia dan UNTAET (United Nations Transitional Administration in East Timor / Pemerintahan Transisi Perserikatan
Bangsa-Bangsa di Timor Timur) yang mewakili Timor Leste membuat rencana kerja (work plan) untuk mendirikan perbatasan darat Indonesia dan Timor Leste dengan mengacu pada Perjanjian 1904 antara Belanda dan Portugal dan Permanent Commission Award (PCA) 1914 (Handoyo, Sri, 2014, h. 178). Selanjutnya pada tahun 2001, joint organization untuk membangun batas negara internasional dibentuk oleh kedua negara, Indonesia dan UNTAET mewakili Timor Leste.

Pada 20 Mei 2002, Timor Leste resmi menjadi negara merdeka dan bernama Republik Demokratik Timor Leste (RDTL). Pada tahun ini juga, Indonesia dan Timor Leste melaksanakan Joint activity dan mulai melaksanakan Joint Interpretation terhadap Perjanjian 1904 dan reconnaissance survey untuk secara bersama-sama menelusuri temuantemuan di lapangan. Pembinaan hubungan kerjasama perbatasan antara Republik Indonesia dengan Negara baru Republica Democratic Timor Leste (RDTL) diwujudkan melalui pelaksanaan persidangan Joint Border Committee (JBC) antara RI-RDTL dan ditindaklanjuti dengan persidangan Pertama Joint Border Commitee (JBC) Meeting Between the Goverment of the Republica of Indonesia and the Goverment of the Republica Demokcratic Timor Leste (RDTL) yang dilaksanakan di Jakarta pada tanggal 1819 Desember 2002 (Pertahanan, 2007). Pada persidangan JBC I RI-RDTL tersebut, dicapai kesepakatan oleh kedua pihak untuk membentuk 4 (empat) Technical Sub-Committee (TSC) dan Border Liaison Committee (BLC), yakni :

a. Technical Sub-Committee on Border Demarcation and Regulation (TSC-BDR) atau Sub-Komite Teknis Pengaturan Perbatasan dan Demarkasi (dikoordinir oleh Bakorsurtanal dan Ditwilhan-Dephan). 
b. Technical Sub-Committee on Cross-Border Movenment of Persons and Goods, and Crossings (TSC-CBMPGC) atau Sub-Komite Teknis Perlintasan Orang dan Barang, serta Perlintasan Batas (dikoordinir oleh Deperindag).

c. Technical Sub-Committee on police Cooperation (TSC-PC) atau SubKomite Teknis kerjasama Kepolisian (dikoordinir oleh Mabes Polri dan Polda NTT).

d. Technical Sub-Committee on Border Security (TSC-BS) atau SubKomite Teknis Keamanan Perbatasan (dikoordinir oleh Mabes TNI dan Pangdam IX Udayana).

e. Border Liaison Committee (BLC) atau Komite Perantara Perbatasan (dikoordinir oleh Wakil Gubernur Nusa Tenggara Timur dengan para anggotanya terdiri dari Pemerintah Kabupaten Perbatasan NTT dan beberapa instansi teknis di tingkat pusat selaku peninjau) (Pertahanan, 2007).

Pada awal 2003, Indonesia - Timor Leste melaksanakan survey bersama CDBRF ( Common border geodetic datum reference frame / Datum dan kerangka referensi batas bersama ) dan pada 9 Juni 2003 joint delineation survey dimulai yang kemudian menghasilkan 907 titik batas yang telah diverifikasi dan diterima oleh Indonesia dan Timor Leste. Pada saat ini, 8 titik batas masih menyisakan masalah (Handoyo, Sri, 2014, h. 178).

Pada Juni 2004, Joint interim report dihasilkan terdiri dari 3 volume yaitu Volume 1 berisi results of the land border delineation, Volume 2 berisi description of Process of Land and border delineation dan Volume 3 mengenai Joint compilation of refrence and auxiliary documents. Pada September-Oktober 2004, joint delineation survey dilanjutkan terutama di wilayah Barat (Okusi) dan menghasilkan sekitar 250 kordinat titik batas yang belum di verifikasi dan diterima bersama (Handoyo, Sri, 2014, p. 178).

Pada Oktober 2004, TSC-BDR (Technical Sub-Committee on Border Demarcation and Regulation / SubKomite Teknis Pengaturan Perbatasan dan Demarkasi) bertemu di Yogyakarta, Indonesia untuk mendiskusikan solusi bagi 8 titik batas yang belum diverifikasi dan diterima bersama. Pertemuan ini berhasil menyelesaikan 5 titik batas sedangkan 3 titik batas masih tersisa yaitu Noel Besi, Biajel Sunan (barat) dan Dilumil/Memo (Timur) (Handoyo, Sri, 2014, h. 178).

Pada 8 April 2005, Indonesia yang diwakili oleh Menteri Luar Negeri Republik Indonesia, Dr. N. Hassan Wirajuda dan Timor Leste yang diwakili oleh Menteri luar negeri Republik Demokratik Timor Leste, Dr. Jose Ramos Horta menandatangani Provisional Agreement yaitu Persetujuan Sementara antara Pemerintah Republik Indonesia dan Pemerintah Republik Demokratik Timor Leste mengenai perbatasan darat. Persetujuan Sementara tersebut ditandatangani di Dili. Dasar hukum dari perjanjian tersebut adalah :

1. Konvensi Perbatasan antara Portugis dan Kerajaan Belanda di Pulau Timor atau disebut Traktat/Treaty 1904 yang di tandatangani di Den Haag pada Tanggal 1 Oktober 1904

2. Arbitral Award Rendered in Execution of the compromis yang ditandatangani di Den Haag tanggal 3 April 1913, antara Belanda dan Portugal mengenai masalah perbatasan yang menjadi bagian kepemilikan kedua negara terhadap Pulau Timor yang di tandatangani di Paris pada tanggal 25 Juni 1914 (Kohne, 2014)

Selanjutnya pada 30 Agustus, 2005, survei demarkasi gabungan (Joint demarcation survey) dilakukan dan 
ditemukan 50 titik batas baru. Survey ini merupakan kelanjutan dari survey pertama yang dilaksanakan di dua titik batas di jembatan Motaain (Handoyo, Sri, 2014, h. 178).

Sepanjang tahun 2008-2012, Indonesia - Timor Leste berupaya menyelesaikan 3 titik batas yang belum terselesaikan yaitu segmen Noel Besi/Citrana, Manusasi/Oben dan segmen Dilumil/Memo (Handoyo, Sri, 2014, p. 178). Negosiasi Indonesia - Timor Leste di tahun 2013 baru dapat menyelesaikan segmen Dilumil/Memo melalui Addendum PA 2005 (Lailissaum, Pemotretan Udara Wilayah Unresolved Segment Perbatasan RI-RDTL dalam Rangka Penyelesaian Sengketa Batas Negara, 2015). Sejak tahun 2013 hingga 2017 masih tersisa dua segmen yang belum selesai yaitu segmen Noel Besi/Citrana dan Manusasi/Oben (lihat gambar 2 dan gambar 3)

Gambar 2. Segmen Noel Besi/Citrana Dan Manusasi/Oben

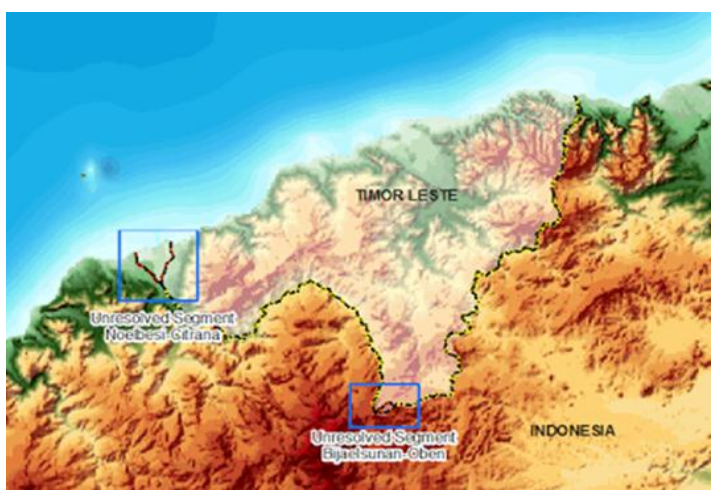

Sumber:Lailissaum, wilayahnegara.blogspot.co.id, 2017

Kawasan Noel Besi/Citrana memiliki wilayah seluas 1000 hektar. Lahan dekat Kabupaten Kupang dan Distrik Oecusse tersebut sering mejadi sumber konflik sesama petani. Paling tidak sepanjang tahun 2000 an, telah terjadi dua konflik penting di wilayah tersebut yaitu di tahun 2012 dan 2013. Pada 31 Juli 2012, konflik muncul di perbatasan Timur Tengah Utara-Oecussi. Warga desa Haumeni Ana, Kecamatan Bikomi Utara, Kabupaten Timor Tengah Utara, NTT, terlibat bentrok dengan warga Pasabbe, Distrik Oecussi, Timor Leste. Bentrokan ini dipicu oleh pembangunan Kantor Pelayanan Bea Cukai, Imigrasi, dan Karantina (CIQ) Timor Leste di zona netral yang masih disengketakan, bahkan dituduh telah melewati batas dan masuk ke wilayah Indonesia sejauh $20 \mathrm{~m}$. Pihak Timor Leste menebang semua tanaman dan pepohonan di tanah tersebut. Setelah terlibat aksi saling "ejek", warga dari kedua negara kemudian saling lempar batu dan benda tajam sebelum akhirnya ditenangkan oleh aparat TNI perbatasan dan tentara Timor Leste (Raharjo, 2013).

Gambar 3. Peta Timor Leste

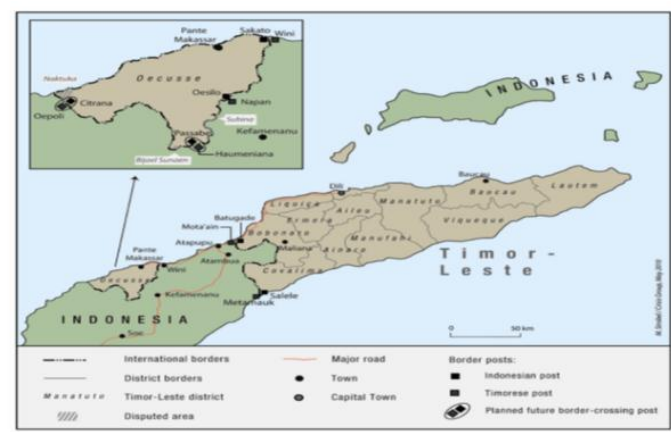

Sumber : International Crisis Group, 2010

Selanjutnya pada 14 Oktober 2013, konflik terjadi antar warga Nelu, Indonesia dengan warga Leolbatan, Timor Leste. Konflik dipicu oleh tindakan Pemerintah Republik Demokratik Timor Leste yang membangun jalan di dekat perbatasan Indonesia-Timor Leste. Menurut warga Timor Tengah Utara, jalan tersebut telah melintasi wilayah NKRI sepanjang $500 \mathrm{~m}$ dan menggunakan zona bebas sejauh $50 \mathrm{~m}$. Padahal berdasarkan nota kesepahaman kedua negara pada tahun 2005, zona bebas ini tidak boleh dikuasai secara sepihak, baik oleh Indonesia maupun Timor Leste. Selain itu, pembangunan jalan oleh Timor Leste 
tersebut merusak tiang-tiang pilar perbatasan, merusak pintu gudang genset pos penjagaan perbatasan milik Indonesia, serta merusak sembilan kuburan orangorang tua warga Nelu, Kecamatan Naibenu, Kabupaten Timor Tengah Utara. Pembangunan jalan baru tersebut kemudian memicu terjadinya konflik antara warga Nelu, Indonesia dengan warga Leolbatan, Timor Leste. Mereka saling lempar batu dan kayu. Aksi ini semakin besar karena melibatkan anggota polisi perbatasan Timor Leste (Cipol) yang turut serta dalam aksi saling lempar batu dan kayu tersebut. Eskalasi konflik semakin meningkat setelah terjadi insiden penggiringan 19 ekor sapi milik warga Indonesia yang diduga digiring oleh warga Timor Leste masuk ke wilayah mereka. 10 warga Indonesia didampingi enam anggota TNI Satgas-Pamtas masuk ke wilayah Timor Leste untuk mencari 19 ekor sapi tersebut (Raharjo, 2013).

Mengapa Segmen Noel Besi/Citrana dan Manusasi/Oben sulit diselesaikan ? Sejauh ini, paling tidak ada dua faktor yang menyebabkannya. Pertama, perbedaan pemakaian landasan hukum dalam menentukan wilayah. Kedua, masalah adat. (www.viva.co.id, 2016) ; (Tuwo, global.liputan6.com, 2017). Untuk kasus Noel Besi/Citrana, pangkal masalahnya adalah perbedaan persepsi antara Indonesia dan Timor Leste mengenai garis awal penarikan batas. Timor Leste menggunakan Uti Possidetis Juris berdasarkan Treaty 1904 sedangkan Indonesia berdasarkan pada sungai dengan garis paling dalam sungai sesuai prinsip hukum internasional. Sementara itu, untuk kasus Bijael Sunan/Oben, kendala utamanya adalah karena masyarakat setempat ingin menyelesaikan persoalan tapal batas dengan hukum adat bukan dengan hukum positif nasional atau hukum internasional. Masyarakat menginginkan agar kesepakatan akan tapal batas terjadi atas dasar kemauan antar masyarakat kedua negara sendiri bukan pemerintah. Selain itu, masyarakat setempat juga merasa ketakutan apabila terjadi kesepakatan antara pemerintah Indonesia dan Timor Leste maka masyarakat tidak bebas menyeberang antar dua negara tersebut. Dengan kata lain, kehidupan sosial dan ekonomi masyarakat setempat dapat terhambat atau terancam. Kekhawatiran masyarakat di Bijael Sunan/Oben tersebut semestinya dapat dipahami mengingat berdasarkan fakta sejarah, komunitas yang ada di Indonesia memiliki hubungan kekerabatan (historis) dengan komunitas yang ada di Timor Leste dan ada kegiatan-kegiatan adat yang perlu dilakukan di wilayah di Timor Leste (Tuwo, global.liputan6.com, 2017).

\section{Upaya Penyelesaian}

Dalam perspektif Hubungan Internasional, sengketa perbatasan darat Indonesia - Timor Leste dapat diselesaikan melalui tiga cara yaitu konfrontasi militer, penggunaan institusi formal dan penggunaan institusi informal. Apabila dilihat dari sisi kemampuan militer, Indonesia jelas memiliki peluang untuk menyelesaikan sengketa dengan konfrontasi militer. Laporan Global Firepower 2017 menyatakan kekuatan militer Indonesia menempati urutan ke-14 dari 106 negara di dunia. Indonesia menghabiskan dana sekitar Rp 92 triliun untuk membiayai kekuatan militernya. Ditambah lagi, angkatan bersenjata Indonesia diperkuat oleh 418 tank, 441 jet tempur, 221 kapal perang, dan 476 ribu tentara aktif (Hasugian, 2017). Karenanya pilihan untuk menggunakan konfrontasi militer sesungguhnya dapat membantu Indonesia untuk menyelesaikan sengketa perbatasan dengan Timor Leste.

Namun pilihan menggunakan
strategi militer sepertinya tidak


digunakan oleh Indonesia karena Indonesia menilai bahwa Timor Leste memiliki political will untuk menyelesaikan sengekta secara damai. Hal tersebut terbukti dengan kunjungan Perdana Menteri (PM) Timor Leste Rui Maria De Araujo ke Jakarta pada 26 Agustus 2015. Dalam Keterangan Pers, Presiden Republik Indonesia, Joko Widodo menyatakan bahwa Indonesia merasa terhormat merupakan negara pertama yang dikunjungi oleh PM Rui Maria De Araujo. Hal tersebut menunjukkan bahwa Timor Leste memandang penting hubungannya dengan Indonesia, tidak hanya sebagai teman atau tetangga terdekat tetapi lebih penting lagi, yaitu sebagai saudara dekat. Dalam pertemuan tersebut, Joko Widodo dan Araujo menyatakan komitmennya untuk menyelesaikan dua titik perbatasan yang belum selesai paling lambat pada akhir tahun 2015 (Setkab, 2015). Persoalan perbatasan darat ini dipandang krusial karena sekitar 53 kepala keluarga asal Timor Leste telah bermukim di Noel Besi bahkan Timor Leste telah membangun sejumlah fasilitas umum di wilayah yang seharusnya kosong sesuai ksepakatan pada tahun 2003 karena wilayah tersebut dinyatakan sebagai zona bebas. Pada pertemuan tersebut, kedua pemimpin negara juga sepakat untuk menyelesaikan sengketa secara damai. Komitmen pemimpin kedua negara tersebut diperkuat lagi dengan pernyataan pers kementerian luar negeri Indonesia yang menyatakan bahwa penyelesaian perbatasan akan dilaksanakan secara damai dan mengacu pada hukum internasional.

Dalam rangka mempercepat penyelesaian sengketa, pada 13 Februari 2017, Menkopolhukam Wiranto dan Menteri Luar Negeri Retno Marsudi mengadakan pertemuan dengan Menteri Perencanaan dan Investasi Strategis Republik Demokratik Timor Leste
Xanana Gusmao di Jakarta. Salah satu hasil dari pertemuan tersebut adalah kedua negara telah sepakat untuk membentuk Senior Official Consultation (SOC) yang akan membahas secara teknis penyelesaian sengketa batas negara. Pertemuan SOC pertama telah dilaksanakan pada 10 Maret 2017 di Bali dan Pertemuan SOC kedua telah dilaksanakan pada 8 April 2017 di Dili.

Gambar 4. Pemimpin Indonesia - Timor Leste bertemu

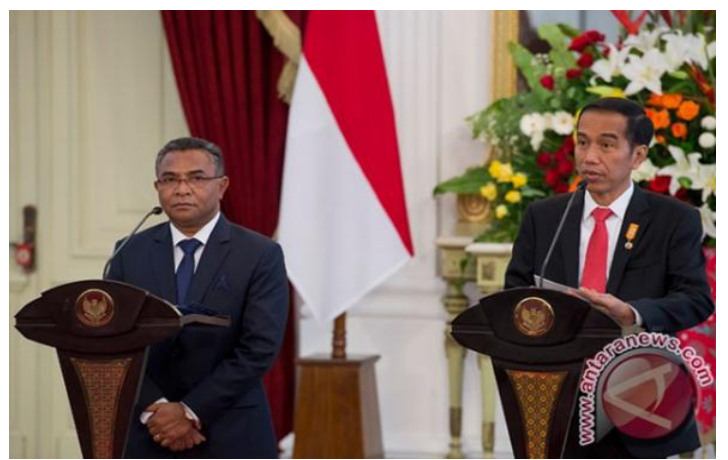

Sumber : Susilo, 2015

Hingga saat ini, negosiasi antara Indonesia - Timor Leste masih berlangsung dan keduanya berkomitmen bahwa sengketa akan diselesaikan dalam waktu dekat. Namun sepertinya, penyelesaian sengketa Timor Leste tidak bisa hanya mengandalkan penggunaan institusi formal seperti traktat/treaty. Penyelesaian konflik perlu juga memperhatikan kepentingan masyarakat lokal yang tinggal di daerah perbatasan segmen Noel Besi/Citrana dan Bijael Sunan/Oben. Terdapat sebuah kemajuan dalam kesepakatan yang dibuat oleh delegasi Indonesia - Timor Leste. Pada pertemuan SOC kedua yang dilaksanakan di Dili pada 7 April 2017, delegasi Timor Leste yang dipimpin oleh H.E. Roberto Sarmento de Oliveira Soares, Wakil Menteri Luar Negeri dan Kerjasama Republik Demokratik Timor Leste dan delegasi Indonesia yang dipimpin oleh H.E. Duta Besar Desra Percaya, Direktur Jenderal Asia Pasifik dan Afrika dari 
Kementerian Luar Negeri Republik Indonesia sepakat untuk menentukan segmen perbatasan yang tersisa dengan mempertimbangkan hubungan sosiokultural dan kesejahteraan masyarakat yang tinggal di dua segmen tersebut (The 2nd Meeting Senior Officials Consultation, 2017)

Memperhatikan kepentingan masyakarat lokal menjadi krusial karena masyarakat adat menuntut agar penentuan tapal batas harus dilakukan melalui sumpah adat. Hal ini terjadi pada kasus segmen Bijael Sunan/Oben. Pada 6 September 2016, puluhan warga bersama tokoh adat Desa Manusasi, Kecamatan Miomafo Barat, Kabupaten Timor Tengah Utara, Nusa Tenggara Timur menggelar ritual di Bukit Bijael Sunan. Ritual tersebut sebagai media untuk berkomunikasi kepada arwah leluhur mengenai sengketa lahan seluas 200 hektare antara warga Miomafo Barat dan warga Ambenu, Timor Leste yang masih memiliki hubungan saudara. Ritual ditandai dengan pemotongan ayam oleh kepala adat yang darahnya kemudian diteteskan di tugu batu menyerupai kepala kerbau milik suku setempat, Valia Anunmut. Sebelum pemotongan ayam, kepala adat melafalkan syair-syair dalam bahasa daerah setempat. Ritual juga ditandai dengan pemotongan sapi yang kepalanya kemudian dikonsumi bersama warga. Menurut Primus Lake, Peneliti Budaya dari Universitas Nusa Cendana (Undana) Kupang, inti upacara ini ialah mereka menyampaikan kepada leluhur bahwa akan ada pembicaraan sengketa lahan antara saudara-bersaudara. Masyarakat di bukit Bijael Sunan menuntut agar penentuan batas wilayah menggunakan pilar pertama yang ditanam oleh Pemerintah Indonesia pada tahun 1966, sehingga wilayah ini termasuk dalam Indonesia. Sebaliknya, Timor Leste menginginkan agar patokan batas menggunakan pilar kedua yang dibangun bersama oleh penjajah Portugis dan Belanda pada 1915, sehingga wilayah ini masuk dalam wilayah Timor Leste. Perbedaan persepsi mengenai penentuan batas menyebabkan masyarakat mengadakan ritual adat untuk menunjukkan kebenaran. Dalam ritual adat tersebut hadir pula staf Kementerian Luar Negeri RI, Elvis Napitupulu. Staf tersebut mengikuti ritual dan mengumpulkan bukti dan keterangan dari warga sebelum persoalan ini dibawa ke perundingan antara pemerintah kedua negara. Hal ini membuktikan bahwa pihak Indonesia telah menunjukkan komitmennya untuk mendengarkan aspirasi masyarakat.

Gambar 5. Ritual Adat di Lahan Sengketa RI-Timor Leste (Bijaelsunan-Oben)

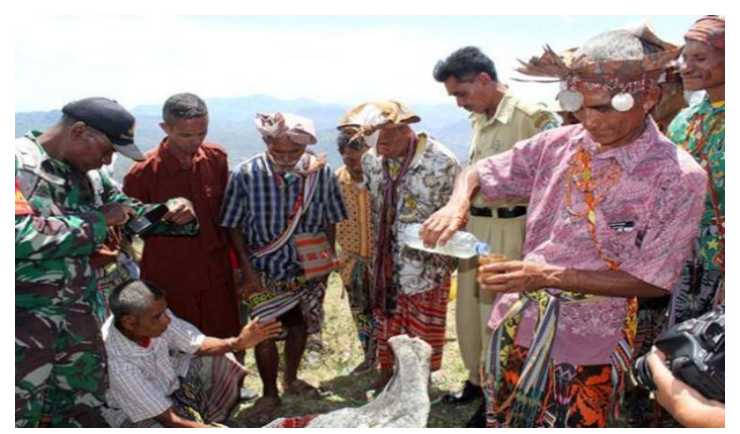

Sumber : mediaindonesia.com, 2016

Berdasarkan kasus ini maka penting bagi Indonesia dan Timor Leste untuk mengunakan nilai, kepercayaan dan norma dalam rangka mendorong penyelesaian batas wilayah. Pemerintah kedua negara perlu berdialog dan mendengarkan masukan masyarakat di lokasi sengketa karena warga di tapal batas yang mempunyai kesamaan budaya dan adat ini ternyata lebih taat dan tunduk pada adat ketimbang hukum positif negara atau internasional. Selama 10 tahun, Indonesia - Timor Leste berunding dengan menitikberatkan pada hukum internasional, hasilnya adalah sengketa perbatasan darat dan laut tidak kunjung tuntas. Karenanya, saat ini, apabila 
pemerintah Indonesia - Timor Leste serius berkomitmen memperhatikan aspirasi masyarakat lokal diharapkan sengketa dapat selesai.

\section{Kesimpulan}

Studi HI menawarkan paling tidak tiga cara dalam menyelesaikan sengketa wilayah perbatasan Indonesia-Timor Leste yaitu konfrontasi militer, pengunaan institusi formal dan institusi informal. Dua cara telah ditempuh oleh Indonesia yaitu penggunaan institusi formal (hukum internasional) dan penggunaan institusi informal (pendekatan norma, kepercayaan dan nilai).
Namun, dalam pelaksanaannya, Indonesia lebih menekankan penggunaan institusi formal daripada institusi informal padahal penggunaan institusi informal sama pentingnya dengan institusi formal terutama untuk kasus segmen Bijael Sunan/Oben. Kedepannya diharapkan, Indonesia menyamakan persepsi dulu dengan masyarakat lokal yang berdiam di daerah perbatasan Indonesia-Timor Leste sebelum membuat kesepakatan formal dengan Timor Leste. Karena ketika kesepakatan tercapai maka masyarakat di daerah perbatasanlah yang menjadi ujung tombak pelaksanaan hasil kesepakatan tersebut.

\section{Daftar Pustaka}

Badan Nasional Pengelola Perbatasan. 2010. Grand Design Pengelolaan Batas Wilayah Negara Dan Kawasan Perbatasan Di Indonesia Tahun 2011 - 2025. Jakarta: Badan Nasional Pengelola Perbatasan (National Authority For Border Management) Republik Indonesia.

Baker, C. D. 2015. Determining the Utility of GIS in border Disputes. California: Faculty of the USC Graduate School University of Southern California .

Handoyo, S. 2011. Geospatial Aspect of The Land Border Between Indonesia And Timor-Leste. Globe Volume 13 No 2 Desember, 175-183.

Handoyo, Sri. 2014. A Brief History of the Boundary Mapping between Indonesia and TimorLeste. History of Cartography: International Symposium of the ICA, 2012 (pp. 165-180). London: Springer.

International Crisis Group. 2010. Timor-Leste: Oecusse and The Indonesian Border. Issue 104 of Asia briefing. policy briefing. Dili/Brussels: International Crisis Group.

Jackson, Robert; Sorensen, Georg. 2005. Pengantar Studi Hubungan Internasional. Yogyakarta: Pustaka Pelajar.

Kohne, Y. 2014. Implementasi Perjanjian Perbatasan RI - RDTL dalam Upaya Penyelesaian Masalah Perbatasan (Studi kasus Di Kabupaten TTU - RI dengan Distrik OecusseRDTL). POLITIKA, Vol. 5, No. 1, Oktober 2014.

Lailissaum, A. 2015. Pemotretan Udara Wilayah Unresolved Segment Perbatasan RI-RDTL dalam Rangka Penyelesaian Sengketa Batas Negara. Simposium Nasional Sains Geoinformasi IV 2015: Penguatan Peran Sains Informasi Geografi dalam Mendukung Penanganan Isyu-Isyu Strategis Nasional (pp. 142-149). Yogyakarta : PUSPICS Fakultas Geografi Universitas Gadjah Mada.

Marsudi, R. L. 2017. Pernyataan Pers Tahunan Menteri Luar Negeri Retno L.P. Marsudi Tahun 2017. Jakarta: Kementerian Luar Negeri Republik Indonesia.

Noveria, Mita; Noor, Firman. 2017. Kedaulatan Indonesia di Wilayah Perbatasan. In M. e. Noveria, Kedaulatan Indonesia di Wilayah Perbatasan: Perspektif Multidimensi (pp. 124). Jakarta: Yayasan Pustaka Obor Indonesia. 
Pertahanan, D. J. 2007. Kajian Optimalisasi Penanganan Wilayah Perbatasan Maritim RIRDTL Dalam Rangka Menjaga Keutuhan NKRI. Jakarta: Departemen Pertahanan Republik Indonesia.

Wendt, A. 1992. Anarchy Is What States Make of It. International Organization, 46, 394-410.

Whitaker, C. P. 2013. Understanding Territorial Disputes: Case Studies Regarding The Disputes Between Ecuador and Peru, Belize and Guatemala, Indonesia and Malaysia, and Laos and Thailand. Boulder: Faculty of Graduate School, University of Colorado.

Wuryandari, G. 2017. Pengelolaan Kedaulatan Negara Dalam Konteks Pertahanan Di Perbatasan RI-Malaysia. dalam M. Noveria, Kedaulatan Indonesia di Wilayah Perbatasan: Perspektif Multidimensi (pp. 63-97). Jakarta: Yayasan Pustaka Obor Indonesia.

\section{Media Online}

2016. mediaindonesia.com. Retrieved Agustus 5, 2017, from mediaindonesia.com: http://mediaindonesia.com/news/read/65488/warga-gelar-ritual-adat-di-lahansengketa-ri-timor-leste/2016-09-06

2016. www.viva.co.id. Retrieved Juli 10, 2017, from www.viva.co.id: http://www.viva.co.id/berita/nasional/725771-sejarah-munculnya-sengketa-wilayahindonesia-timor-leste

2017. nasional.kompas.com. Retrieved September 13, 2017, from nasional.kompas.com: http://nasional.kompas.com/read/2017/o9/12/21195341/tawa-wiranto-xanana-danretno-marsudi-usai-bahas-sengketa-perbatasan

Hasugian, M. R. 2017. www.cnnindonesia.com. Retrieved Juli 20, 2017, from www.cnnindonesia.com: https://www.cnnindonesia.com/nasional/20171005132550-20246335/kekuatan-militer-indonesia-diharapkan-masuk-10-besar-dunia/

Lailissaum, A. 2017. wilayahnegara.blogspot.co.id. Retrieved Oktober 10, 2017, from wilayahnegara.blogspot.co.id: https://wilayahnegara.blogspot.co.id/2017/10/statusterkini-perbatasan-indonesia.html

Raharjo, S. N. 2013. www.politik.lipi.go.id. Retrieved Juli 8, 2017, from www.politik.lipi.go.id: http://www.politik.lipi.go.id/in/kolom/politik-internasional/899-konflik-komunal-diperbatasan-indonesia-timor-leste-dan-upaya-penyelesaiannya.html

Romualdus, S. (2016, Januari 26). indonesiasatu.co. Retrieved Juli 20, 2017, from indonesiasatu.co: http://indonesiasatu.co/detail/timor-leste-sepakat-percepatpenyelesaian-konflik-perbatasan

Setkab, H. 2015. setkab.go.id. Retrieved Juli 20, 2017, from setkab.go.id: http://setkab.go.id/keterangan-pers-presiden-joko-widodo-pada-kunjungankenegaraan-pm-timor-leste-di-istana-merdeka-jakarta-26-agustus-2015/

Susilo, J. 2015. www.antaranews.com. Retrieved Juli 20, 2017, from www.antaranews.com: http://www.antaranews.com/berita/514415/indonesia-timor-leste-bicarakan-masalahperbatasan

Sutisna, Sobar; Handoyo, Sri. 2006. big.go.id. Retrieved Juli 10, 2017, from big.go.id: http://big.go.id/assets/News/Artikel-pdf/Paper\%20IBRU\%2oBangkok.pdf

2017. The 2nd Meeting Senior Officials Consultation, J. P. timor-leste.gov.tl. Retrieved Juli 20, 2017, from timor-leste.gov.tl: http://timor-leste.gov.tl/wpcontent/uploads/2017/05/Joint-Press-Release-of-the-2nd-Consultation-TL-RI-Dili-o6o8-April-17-MaC.pdf

Tuwo, A. G. (2017, Maret 13). global.liputan6.com. Retrieved Juli 20, 2017, from global.liputan6.com: http://global.liputan6.com/read/2884636/mei-2017-masalahperbatasan-ri-timor-leste-ditargetkan-selesai 
